\title{
Preconcentration and analysis of gold from cyanide solutions with the use of a microcolumn packed with the phosphine oxide Cyanex $921^{1}$
}

\author{
A.G. Coedo*, M.T. Dorado, F.J. Alguacil, I. Padilla \\ Centro Nacional de Investigaciones Metalurgicas (C.S.I.C.), Avda. Gregorio del Amo 8, 28040 Madrid, Spain \\ Received 29 March 1995; revised 6 September 1995; accepted 7 September 1995
}

\begin{abstract}
The phosphine oxide Cyanex 92I (tri- $n$-octylphosphine oxide) was found to be a very efficient extractant for gold from aurocyanide aqueous solutions. A system comprising a microcolumn packed with this new reagent was developed for the separation and enrichment of gold. Because of the high selectivity of the developed system it is possible to analyze gold in the presence of an excess of other metals and/or in high ionic strengh solutions.
\end{abstract}

Keywords: Gold; Preconcentration; ICP-MS

\section{Introduction}

Gold is one of the elements which has maintained a stable (high) price over the past few years and therefore there has been renewed interest in finding new resources to recover this valuable metal. Unfortunately, gold levels in both, raw materials and waste products are normally very low, thus it is desirable and in many cases necessary to make use of analytical methods that ensure high selectivity, sensitivity, accuracy and specd. One of the possibilitics for analyzing thesc low concentrations of element is by the develop-

\footnotetext{
* Corresponding author.

' Presented at the Symposium on Analytical Sciences, held in Paris, France, March 1995.
}

ment of a manifold for performing rapid analyte enrichment that could be easily incorporated with atomic spectroscopy techniques.

Solvent extraction, in contrast, is a well developed discipline applied to the recovery and processing of gold from aqueous solutions and also in analytical chemistry [1]. The development of new commercially available extractants has opened up new fields of application for this technique. This has produced literature proposing new extractants or extraction systems for recovering gold from different aqueous solutions $[2,3]$.

Recently, several papers have been published describing the determination of gold by atomic spectroscopy techniques (see e.g. Ref. [4]). The present work centres on the rapid preconcentration and determination by inductively-coupled plasma mass spectrometry (ICP-MS) of gold from 
cyanide solutions, as obtained in the conventional leaching processes used to recover gold. The manifold designed for this purpose incorporated a microcolumn packed with the phosphine oxide Cyanex 921, with an analyte enrichment scheme based on a process application of this organic reagent in the recovery of gold by the liquid liquid extraction technique [3]. The developed system is also suitable to be used in on-line flow-injection analysis.

\section{Experimental}

The phosphine oxide Cyanex 921 (tri- $n$ octylphosphine) used in the present work is a white solid. Its structure is $\mathrm{R}_{3} \mathrm{PO}$, in which $\mathrm{R}$ represents the $n$-octyl chains, and its molecular weight is 386 [4]. The reagent was kindly supplied by Cyanamid Ibérica S.A. and was used as obtained by the manufacturer. The reagent was loaded in microcolumns of different lengths which had been handmade from a piece of teflon tubing of $3 \mathrm{~mm}$ i.d. The effective reagent volume was varied from $35 \mu 1$ to $280 \mu 1$ and the reagent was held in position by glass-wool stoppers. All the chemicals used were of Suprapur grade from E. Merck.

A standard gold stock solution of $100 \mathrm{mg}^{-1}$ was prepared by dissolving $0.1000 \pm 0.0001 \mathrm{~g}$ of pure gold with $16 \mathrm{ml}$ of hydrochloric acid and 4 $\mathrm{ml}$ of nitric acid, and diluting to $1000 \mathrm{ml}$ with diluted hydrochloric acid $(1+4)(\mathrm{v} / \mathrm{v})$. Alternatively, $0.1463 \pm 0.0001 \mathrm{~g}$ of gold potassium cyanide was dissolved with water and diluted to $1000 \mathrm{ml}$.

An ELAN 5000 ICP-MS spectrometer (PerkinElmer SCIEX) with an ELAN 5000 computer system was used. The operating conditions of the spectrometer are given in Table 1.

\section{Results and discussion}

A preliminary preconcentration investigation was carried out by a gravity-controlled minicolumn method. Recoveries of $1 \mathrm{mg}$ of gold from a Cyanex 921 column ( $3 \mathrm{~cm}$ long, $1 \mathrm{~cm}$ i.d.) were investigated. It was proved that gold was quantitatively retained from aqueous solutions and from both low and high ionic strength solutions. The following eluants were investigated for the rapid elution of $\mathrm{Au}$ : water, $5 \mathrm{mM} \mathrm{KCN}, 0.5-1.0 \mathrm{M}$ $\mathrm{NaCN}, 0.5-1.0 \mathrm{M} \mathrm{NaCl}, 0.1-0.5 \mathrm{M} \mathrm{HCl}$ and $0.1-0.5 \mathrm{HNO}_{3}$. It was found that a $5 \mathrm{mM} \mathrm{KCN}$ solution was the best eluant amongst these and it was therefore selected for further experiments. Elution of $1 \mathrm{mg}$ of $\mathrm{Au}$ which had been retained on the minicolumn was first investigated by using a continuous flow of the eluant, and the elution stage showed recoveries between 97 and 100\% with $20 \mathrm{ml}$ of the eluant. Then, circulation of the eluant was carried out to minimize the volume of the eluant: $5 \mathrm{ml}$ of the eluant was circulated four times through the minicolumn. Elution behaviors for the continuous flow $(20 \mathrm{ml})$ and for four circulations of $5 \mathrm{ml}$ were different. By using circulation of the eluant the eluted gold does not increase from the first step to the last. From the results obtained with this preliminary study, optimization of the preconcentration system was carried out by using horizontal microcolumns and peristaltic pumps. A schematic diagram of the developed system is shown in Fig. 1.

\subsection{Influence of aqueous ionic strength}

Aqueous solutions of different ionic strength were studied to investigate the influence of ionic strength on gold retention. The total quantity of gold loaded in the microcolumns, by circulating different volumes of gold solutions containing 10 or $100 \mathrm{ng} \mathrm{ml}^{-1}$ of $\mathrm{Au}$, ranged from $10 \mathrm{ng}$ to 500 ng. These initial gold solutions were: water, $5 \mathrm{mM}$ $\mathrm{KCN}, 1 \mathrm{M} \mathrm{LiCl}, 0.5-1.0 \mathrm{M} \mathrm{NaCl}$ and $20 \mathrm{mM}$ $\mathrm{NaCN}$, whereas effective microcolumn capacities varied from 35 to $280 \mu \mathrm{l}$.

Typical results are shown in Table 2 . The great effectiveness of the phosphine oxide and the devised manifold as an enrichment system for gold from different aqueous solutions can be seen. In all the other cases which are not shown in the Table quantitative recoveries were also obtained. Thus the phosphine oxide seems to be an effective organic reagent to load gold from these media. The chemical nature of the phosphine oxide sug- 
Table 1

Operating conditions for the ELAN 500

\begin{tabular}{ll} 
Nebulizer & Ryton crossflow \\
Interface cones & Pt sampler and skimmer \\
R.f. power & $1200 \mathrm{~W}$ \\
Plasma Ar flow & $12.01 \mathrm{~min}^{-1}$ \\
Auxiliary Ar flow & $1.001 \mathrm{~min}^{-1}$ \\
Nebulizer Ar flow & $1.201 \mathrm{~min}^{-1}$ \\
Sample flow & $0.901 \mathrm{~min}^{-1}$ \\
Ion optics settings & Standard \\
Dwell time & $125 \mathrm{~ms}$ \\
No. of sweeps & 125 \\
Number of replicates & 4 \\
Resolution & $0.6 \mathrm{amu}$ \\
Analysis time per sample & $65 \mathrm{~s}$ \\
\hline
\end{tabular}

gests that this reagent loads gold by means of a solvation reaction through the donation of an electron pair on the oxygen atom of the organic molecule [3-6]; if one considers that gold is present in the cyanide aqueous solution as the aurocyanide complex, then the following reaction for gold loading can be proposed:

$$
\begin{array}{r}
\mathrm{R}_{3} \mathrm{PO}+\mathrm{Me}_{\mathrm{aq}}^{+}+\mathrm{Au}(\mathrm{CN})_{2}^{-} \mathrm{aq}_{4} \leftrightarrow \mathrm{R}_{3} \mathrm{PO} \cdots \mathrm{Me}^{+} \\
\mathrm{Au}(\mathrm{CN})_{2}
\end{array}
$$

The phosphine oxide $\left(\mathrm{R}_{3} \mathrm{PO}\right)$ solvated the ion pair represented by $\mathrm{Me}^{+} \mathrm{Au}(\mathrm{CN})_{2} \quad\left(\mathrm{Me}^{+}: \mathrm{Li}^{+}, \mathrm{Na}^{+}\right.$,
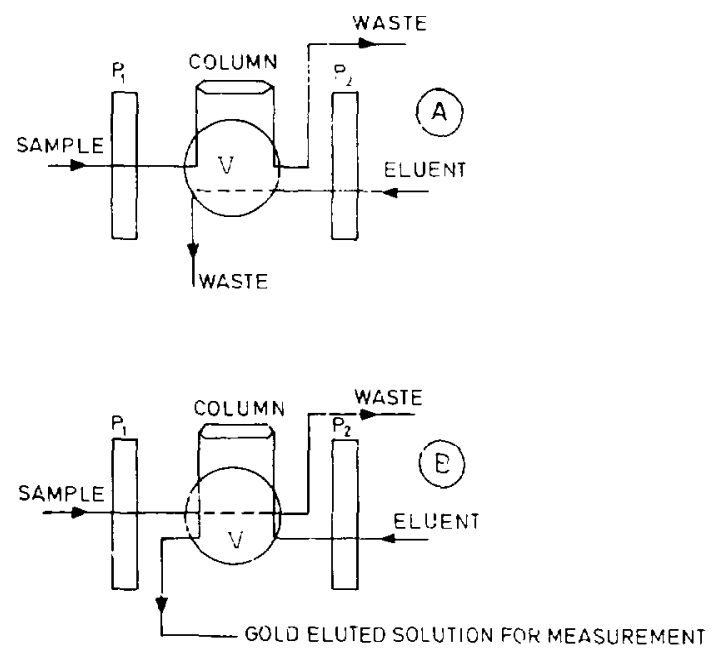

Fig. 1. Schematic diagram of the microcolumn preconcentration system. (A) Preconcentration step: $P_{1}$, running; $P_{2}$, stopped; $V$, position 1 . (B) Elution step: $\mathbf{P}_{1}$, stopped; $\mathbf{P}_{2}$, running; $\mathrm{V}$, position 2 .
Table 2

Effect of aqueous ionic strength on gold retention

\begin{tabular}{lcrl}
$\begin{array}{l}\text { Aqueous } \\
\text { solution }\end{array}$ & $\begin{array}{l}\text { Effective } \\
\text { column volume } \\
(\mu 1)\end{array}$ & $\begin{array}{l}\text { Gold } \\
\text { loaded } \\
\text { (ng) }\end{array}$ & $\begin{array}{l}\% \text { Gold } \\
\text { breakthrough }\end{array}$ \\
\hline Water & 70 & 1000 & 0 \\
$5 \mathrm{mM} \mathrm{KCN}$ & 70 & 10 & 0 \\
$20 \mathrm{mM} \mathrm{NaCN}$ & 35 & 500 & 0 \\
$1 \mathrm{M} \mathrm{LiCl}$ & 140 & 50 & 0 \\
$1 \mathrm{M} \mathrm{NaCl}$ & 280 & 100 & 0 \\
\hline
\end{tabular}

$\left.\mathrm{K}^{+} \ldots\right)$.

\subsection{Gold elution}

The elution of gold from the packed column was accomplished, according to the preliminary study, with low ionic strength aqueous solutions. Different column capacities were used, ranging from $35 \mu \mathrm{l}$ to $280 \mu \mathrm{l}$, and the columns were packed with the phosphine oxide Cyanex 921. All of the columns were loaded with $100 \mathrm{ng}$ of gold from aurocyanide solutions and $5 \mathrm{mM} \mathrm{KCN}$ solution ( $2 \mathrm{ml}$ each stage) was used as eluant. results obtained are represented in Fig. 2, which shows the cumulative amount of gold eluted in each stage. It can be observed from these results that 5 $\mathrm{mM} \mathrm{KCN}$ solution is an efficient eluant for gold although the effective column volume influences gold elution at each stage. With the low column capacities, more than $95 \%$ gold elution can be readily achieved at the first stage although two stages are required $(4 \mathrm{ml})$ to obtain complete quantitative gold elution. As the column effective capacity becomes greater the percentage of gold eluted in the first stage becomes lower, it being necessary to use more eluant (more than two stages of $2 \mathrm{ml}$ ) to ensure quantitative gold elution. However, under the present experimental conditions no more than three stages were ever needed.

\subsection{Cycle experiments}

According to results obtained from gold enrichment-elution experiments, further tests were carried out on the basis of the study of the column effectiveness with a number of complete and accumulative retention-clution cycles. 
Experiments were performed in a microcolumn of $70 \mu \mathrm{l}$ effective volume packed with the phosphine oxide Cyanex 921. Gold loaded in each cycle was $100 \mathrm{ng}$ whereas elution was carried out with two stages ( 2 ml each) of a $5 \mathrm{mM} \mathrm{KCN}$ aqueous solution. The results from the cycle experiments are presented in Table 3. It can be seen from these data that there is no appreciable change in gold retention after a number of consecutive tests. In the case of the elution step the effectiveness of the first elution stage is always no less than $96 \%$ and in all the cycles complete gold elution can be achieved in less than two stages. The performance of the oxide Cyanex 921 column appeared to be good enough.

\subsection{Influence of the flow rates of the solutions}

Several experiments were conducted to study the effect of the flow rate of the different aqueous solutions used in the gold enrichment-elution stages. Gold loading experiments were performed with a $70 \mu \mathrm{l}$ effective column volume packed with the oxide Cyanex 921; on this column gold solutions were circulated at different flow rates. $\mathrm{Re}$ sults obtained showed that there was no significant influence of this variable on gold retention which was in all cases $100 \mathrm{ng}$. Tests in the elution step were carried out on a similar column as described above and loaded with $100 \mathrm{ng}$ of gold; as eluant a $5 \mathrm{mM} \mathrm{KCN}$ aqueous solution

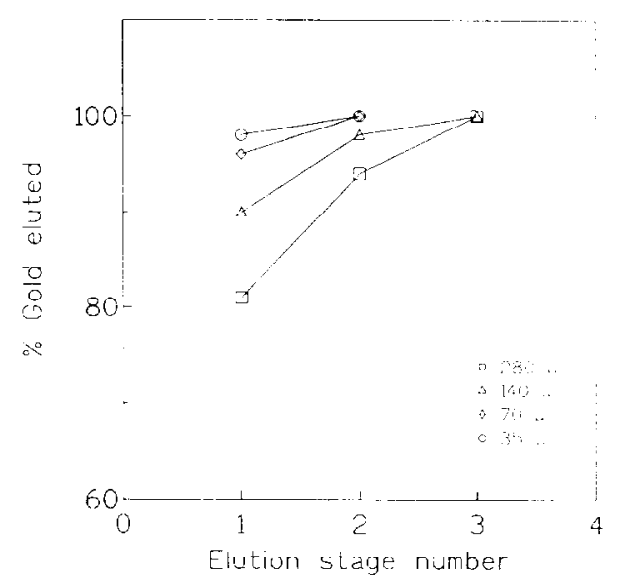

Fig. 2. Elution of $100 \mathrm{ng}$ of gold from microcolumns of different capacities.
Table 3

Gold retention elution per cycle. 10 consecutive cycles through the same microcolumn

\begin{tabular}{|c|c|c|c|}
\hline \multirow[t]{2}{*}{ Cycle } & \multirow{2}{*}{$\begin{array}{l}\text { "//" Gold } \\
\text { breakthrough }\end{array}$} & \multicolumn{2}{|c|}{$\%$ Gold elution } \\
\hline & & 1st stage & 2nd stage \\
\hline 1 & 0 & 96 & 3 \\
\hline 2 & 0 & 98 & 2 \\
\hline 3 & 0 & 96 & 4 \\
\hline 4 & 0 & 96 & 5 \\
\hline 5 & 0 & 97 & 2 \\
\hline 6 & 0 & 98 & 4 \\
\hline 7 & 0 & 96 & 2 \\
\hline 8 & 0 & 97 & 3 \\
\hline 9 & 0 & 98 & 3 \\
\hline 10 & 0 & 96 & 3 \\
\hline
\end{tabular}

was used. Results obtained from these series of experiments are shown in Fig. 3. It can be deduced that the elution flow rate has an influence on the percentage of gold eluted. With the use of a higher flow rate gold elution is greatly improved both in terms of the percentage of gold eluted in each stage and also in the number of stages necessary to complete the gold unloading of the column.

\subsection{Selectivity of the reagent}

In normal practice it is usual to find many other elements accompanying gold in the treated solutions [7]. Thus in the present work the selectivity of the system Cyanex 921 -gold was studied against different metallic cations.

Experiments were carried out with a microcolumn of $70 \mu \mathrm{l}$ effective capacity and with this device $5 \mathrm{ml}$ of a multielement solution containing $100 \mathrm{ng} \mathrm{ml}^{-1}$ of each of the elements $\mathrm{Ag}, \mathrm{Al}, \mathrm{B}$, $\mathrm{Ba}, \mathrm{Bi}, \mathrm{Ca}, \mathrm{Cd}, \mathrm{Co}, \mathrm{Cr}, \mathrm{Cu}, \mathrm{Ga}, \mathrm{In}, \mathrm{Li}, \mathrm{Mg}, \mathrm{Mn}$, $\mathrm{Ni}, \mathrm{Pb}, \mathrm{Sr}, \mathrm{Ta}, \mathrm{Zn}$ and $\mathrm{Fe}$ was passed through the column at a flow rate of $1 \mathrm{ml} \mathrm{min} \mathrm{'.} \mathrm{Results}$ obtained showed that there is no metal retention, indicating the high selectivity of the system for gold and thus also allowing the enrichment of this metal from multiclemental aqueous solutions. 


\subsection{ICP-MS measurements}

The good results obtained from this work open up new possibilities for studying the application of this system to quantitative analysis from diluted gold solutions. Quantities of gold ranging from $25 \mathrm{ng}$ to $1000 \mathrm{ng}$ were loaded on the microcolumn and eluted with $2 \mathrm{ml}$ of $5 \mathrm{mM} \mathrm{KCN}$ solution. The eluted solutions were measured by ICP-MS using the operating conditions listed in Table 1, and the corresponding plot of gold concentration vs. ion count is represented in Fig. 4 The slope was 36.5 and the correlation coefficient 0.9993 . The detection limit (defined as the concentration of a solution giving an absorbance equal to three times the standard deviation of the blank) was $0.5 \mathrm{ng}$ of gold in $2 \mathrm{ml}$. At levels five times higher than the detection limit, an RSD $(n=6)$ of about $2 \%$ was obtained.

Table 4 shows the gold recovered in $2 \mathrm{ml}$ of final volume from different injected volumes of an Au spiked solution containing $10 \mathrm{ng} \mathrm{ml}^{-1}$ of $\mathrm{Au}$. Injected volumes from $2.5 \mathrm{ml}$ to $100.0 \mathrm{ml}$ were tested and a volume of $2 \mathrm{ml}$ of eluent was always employed.

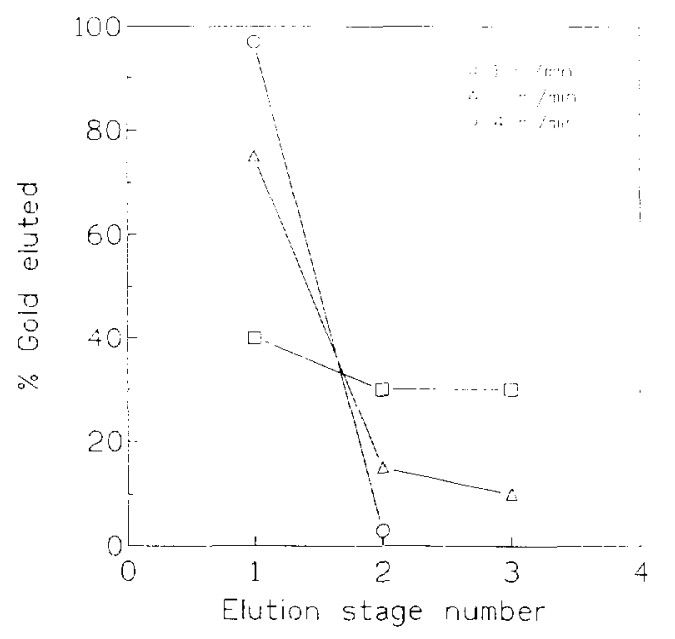

Fig. 3. Influence of the eluant flow rate on gold elution.

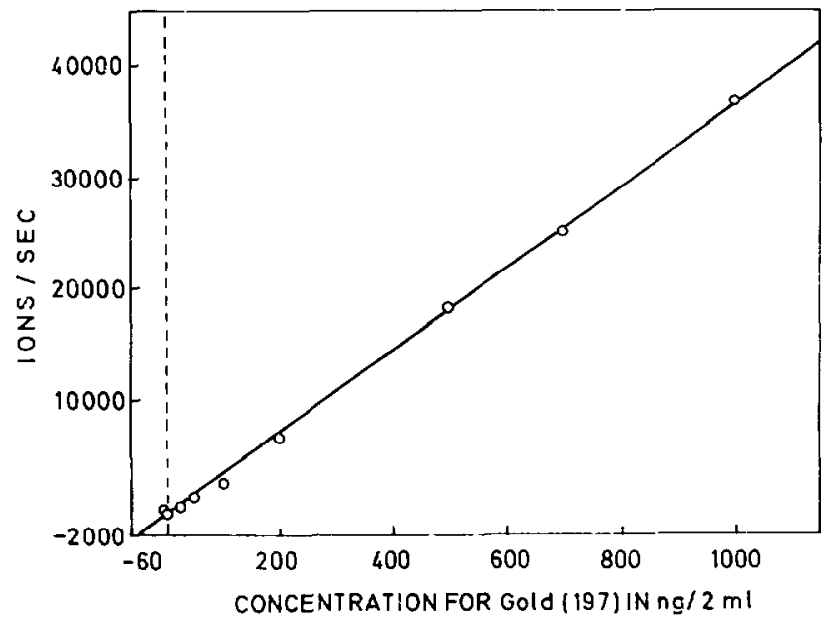

Fig. 4. ICP-MS gold calibration graph. Calibration report: analyte, ${ }^{197} \mathrm{Au}$; slope, 36.5219: intercept, -60.9545 ; root mean square, 496.4725: correlation coefficient, 0.9993 .

\section{Conclusions}

In the present work a new manifold was developed for gold determination from aqueous solutions. Gold loading on the column packed with Cyanex 921 is not influenced by the ionic strength of the solution whereas the gold elution is influenced by the ionic strength of the eluant, the column length and the eluant flow rate. Elution is improved with a lower effective volume column and a higher eluant flow rate. The column packed with phosphine oxide Cyanex 921 seems to be very stable, with equal loss of gold retention-elution performance with accumulative retention-

Table 4

Gold recovered in the first $2 \mathrm{ml}$ of eluant from different injected volumes of a Au spiked solution containing $10 \mathrm{ng}$ $\mathrm{ml}$ ' of $\mathrm{Au}$

\begin{tabular}{|c|c|c|c|}
\hline \multicolumn{2}{|c|}{ Gold loaded on the column } & \multicolumn{2}{|c|}{ ICP-MS results $(n=6)$} \\
\hline Volume $(\mathrm{ml})$ & $\mathrm{Au}(\mathrm{ng})$ & $\mathrm{Au}(\mathrm{ng})$ & SD \\
\hline 2.5 & 25 & $14.12(96.5 \%)$ & 0.40 \\
\hline 5.0 & 50 & $4900\left(98.0^{0} \%\right)$ & 1.05 \\
\hline 10.0 & 100 & $96.70(96.7 \%$ & 1.55 \\
\hline 25.0 & 250 & $243.75(97.5(1)$ & 2.80 \\
\hline 50.0 & 500 & $491.50(98.2 \%)$ & 6.12 \\
\hline 100.0 & 1000 & $985.00(98.5 \%)$ & 9.82 \\
\hline
\end{tabular}


elution cycles. The system also seems to be very selective against many elements, thus with this manifold for the separation of gold most of the common ions usually present in the aqueous solutions did not interfere. With this system a gold concentration range from $10 \mathrm{ng}$ to $1000 \mathrm{ng}$ was determined by ICP-MS using microcolumns of 70 $\mu 1$ capacity ( $1 \mathrm{~cm}$ long, $3 \mathrm{~mm}$ i.d.). Gold retained in the microcolumns was eluted with $2 \mathrm{ml}$ of diluted cyanide solutions ( $5 \mathrm{mM}$ ). Gold recoveries close to $100 \%$ can be readily achieved. Further designs are under way to couple the devised manifold for on-line FI-ICP-MS analysis of gold from cyanide waste solutions.

\section{Acknowledgement}

The authors thank the Consejo Superior de
Investigaciones Científicas (C.S.I.C., Spain) for financial support to carry out this work.

\section{References}

[1] J. Rydberg, C. Musikas and G.R. Choppin, Principles and Practices of Solvent Extraction, M. Dekker, New York, 1992.

[2] C. Caravaca and F.J. Alguacil, Hydrometallurgy, 31 (1992) 257.

[3] F.J. Alguacil, C. Caravaca, A. Cobo and S. Martinez, Hydrometallurgy, 35 (1994) 41

[4] A.G. Coedo, M.T. Dorado, E. Escudero and I.G. Cobo, At. Spectrosc., 15 (1994) 78.

[5] W.A. Rickelton and R.J. Boyle, Sep. Sci. Technol., 23 (1988) 1227.

[6] G.M. Ritcey and A.W. Ashbrook, Solvent Extraction, Part 1, Elsevier, Amsterdam, 1984

[7] J. Marsden and I. House, The Chemistry of Gold Extraction, Ellis-Horwood, Chichester, 1992. 